Marketplace is provided as a service to readers using text and images from the manufacturer, supplier or distributor and does not imply endorsement by Vital. Normal and prudent research should be exercised before purchase or use of any product mentioned.

\section{GIVE YOUR SURGERY A MODERN LOOK}

Not everyone wants to purchase a complete Treatment Centre when sometimes it's only the chair that needs replacing. Takara Belmont's Pro II chair can be sold independently of the Cleo treatment centre and has some unique benefits.

The folding leg rest gives the chair a modern look that is also extremely practical; its compact size makes surgeries look less cramped and the design is a lot less intimidating for patients during consultation.
Three pre-set positions, back and base movements are operated by foot control thus eliminating a cross infection risk. The seamless upholstery also benefits cross infection control, providing no available hiding places for bacteria, ensuring optimum hygiene. If your chair is starting to date your surgery call Takara Belmont on 02075150333 or email dental@takara.co.uk. Alternatively, all products are available to view at either of Belmont's showrooms located in London (020 7515 0333) and Manchester (0161 743 9992).

\section{D LINGUAL ORTHODONTICS}

Non-visible lingual braces have been available for some time but despite the obvious aesthetic advantages for the wearer, ease of use, cost effectiveness and patient comfort have all been cited as drawbacks by dentists and orthodontists.

A new 2D system by Forestadent has round edges and smooth surfaces, allowing freedom of movement for the tongue - enabling patients to eat and speak without impairment almost immediately after the appliance has been inserted. The self ligating brackets feature a vertical slot for quick and easy archwire insertion.

In addition, the $2 \mathrm{D}$ bracket, which has a total thickness of $1.3 \mathrm{~mm}$ to $1.65 \mathrm{~mm}$, can be bonded directly or indirectly and its clips have been designed to open and close easily.

Call Forestadent on 01908568922.
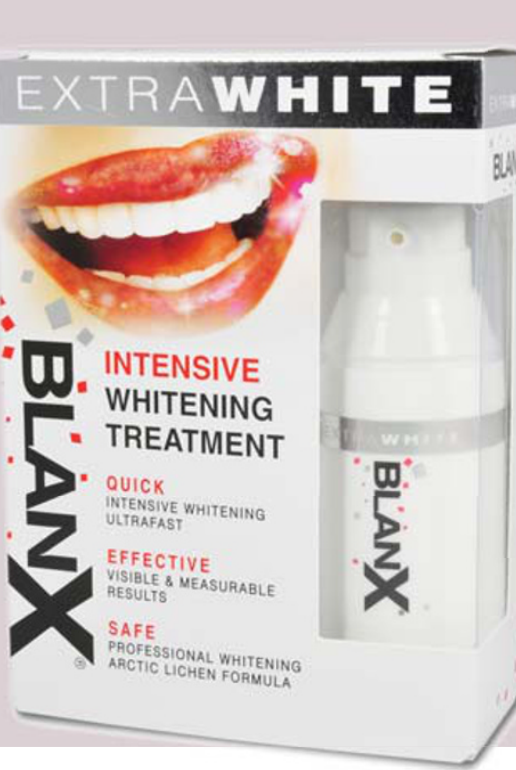

\section{(a)}
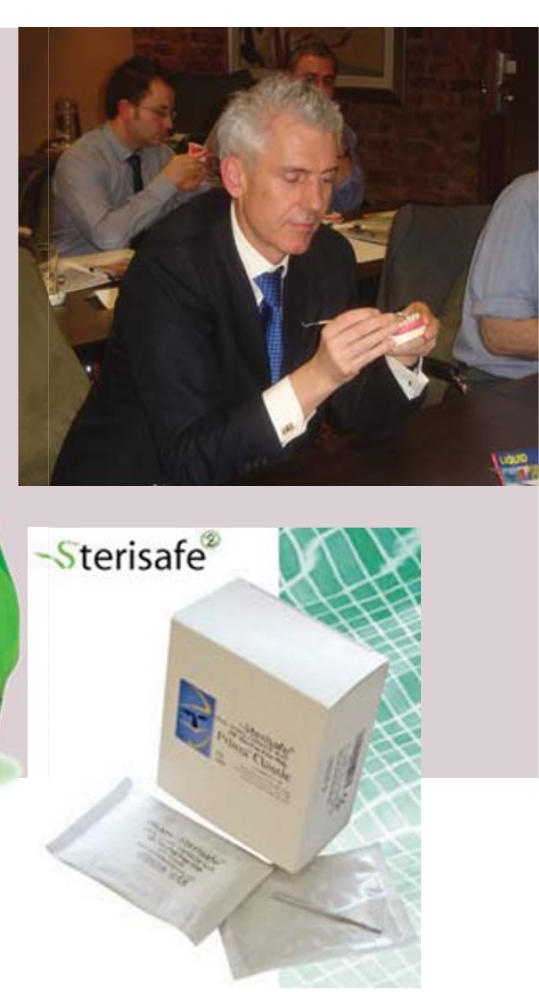

Alcohol free Dentyl pH has introduced Minty Citrus Splash. The mouthwash range has an advanced formula consisting of: a water-based phase incorporating the antibacterial agent Cetylpyridinium Chloride (CPC), and an oilbased solution with natural essential oils, that has to be shaken before use.

When shaken, Dentyl $\mathrm{pH}$ forms a temporary emulsion and the oils mix with the CPC. As the mouthwash is swished and gargled around the mouth, it lifts and absorbs $99.9 \%$ oral bacteria and debris which can then be seen in the sink.

Alcohol Free Dentyl pH Minty Citrus Splash

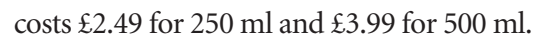
It is available from leading dental wholesalers. Dental surgeries wishing to order directly should call 01923205704.

\section{NO RISK BURS}

Pre-sterile burs are fast becoming a vital element in the battle against cross infection. However, not all single use burs are pre-sterile. Many on the market are supplied as 'factory clean' so it's imperative to sterilise these burs before use. Sterisafe from Prima ensures complete sterility of each individual bur; all you have to do is to unwrap the rotary instrument, pop it in the handpiece and you are ready to go!

Available in diamonds, tungsten carbide or steel rotary instruments the burs are manufactured and packaged in the UK in individual pouches for ease of use. For further information contact Prima Dental Group on (0044) 1452 307171 or visit www.primadentalgroup.com. 